Article

\title{
Sensorial Organization as an Ethics of Space: Digital Media in Everyday Life
}

\author{
Stina Bengtsson \\ Media and Communication Studies, Södertörn University, 14189 Huddinge, Sweden; E-Mail: stina.bengtsson@sh.se
}

Submitted: 31 December 2017 | Accepted: 28 February 2018 | Published: 25 May 2018

\begin{abstract}
This article outlines an analysis of the ethical organization of digital media and social and individual space in everyday life. This is made from a perspective of an 'ethics of the ordinary', highlighting the mundane negotiations and practices conducted to maintain a 'good life' with the media. The analysis shows a sensorial organization of space is conducted in relation to social space, as well as individually. The interviewees use facilities provided by media technologies in order to organize space, as well as organize their media devices spatially in order to construct space for specific purposes, and maintain a good life. These results call for a deepened analysis of the sensorial dimensions of everyday space, in order to understand the ethical struggles of a life with digital media. It is important to include the full spectrum of sensorial experiences in our approach to everyday life and to take the sensorial experiences of ordinary media users into account in our analysis of space as part of an everyday ethics.
\end{abstract}

\section{Keywords}

digital media; ethics; everyday life; phenomenology; sensorial; space

\section{Issue}

This article is part of the issue "Rethinking Media and Social Space", edited by André Jansson and Johan Lindell (Karlstad University, Sweden).

(C) 2018 by the author; licensee Cogitatio (Lisbon, Portugal). This article is licensed under a Creative Commons Attribution 4.0 International License (CC BY).

\section{Introduction}

Media technologies are increasingly entangled in everyday life (Couldry \& Hepp, 2016; Deuze, 2012; Jansson, 2013) and many mundane practices have gradually become dependent on media technologies. How we live with media is in its deepest sense a question of ethics (Couldry, 2006), relating to how we organize our lives with technologies. But how do ordinary media users negotiate what they understand as a good life with the media? How are the ethical dimensions of digital culture practiced on a daily basis, entangled with the myriad of temporalities, spatialities, and materialities constituting everyday life? In this article I address the use of media technologies in everyday life as an ethical organization of space.

My argument in this article follows from an analysis of how people appropriate and organize space individually and socially in order to negotiate the dependencies and affordances that are part of digital culture. Firstly I present an analysis of the sensorial organization of digital media that is maintained in order to control and con- struct space for individual and social purposes in everyday life. Secondly, I call for a developed analysis of the embodied and sensorial dimensions of media technologies in order to understand the ethical practices and performances of life in digital culture. Given the character and fast development of digital technologies it is important to include the full spectrum of sensorial experiences when understanding the way we live with technologies in everyday life. In this we need a materialist and bodily phenomenology in line with that of Merleau-Ponty (1962).

\section{Understanding Ethics of Everyday Life through the Organization of Social Space}

Earlier analyses of media in everyday life have revealed the ethical dimensions of its spatial organization (Bengtsson, 2006). The larger and often stationary analogue media devices; television, radio, telephones, etc., had their permanent positions in specific places in the home and were thus involved in constructing symbolic spaces in the home environment; invisible borders between work space, leisure space, social space and space for solitude, 
etc. Today, mobile and portable digital media do not provide media users with the same possibilities for a neat material organization of space, in the home, at work or school, in social situations etc., since they are 'always on you' (Turkle, 2008), and thus increasingly entangled in various dimensions of human practice.

The current saturation of media in various dimensions of human lives has been discussed as part of the mediatization of culture and everyday life (Couldry \& Hepp, 2016). André Jansson (2013, p. 281) has argued the process of mediatization contains important spatial dimensions and suggests we think of the current state of mediatization in terms of sociospatial regimes of dependence. These regimes include 1) material indispensability and adaptation, 2) premediation of experience and 3 ) normalization of social practice. The first and the third dimension are the most important ones here, the first mainly as vantage point; we know from earlier research that media technologies are immersing into growing areas of everyday practices such as searching, choosing, socializing, dating, etc. (cf. Couldry \& Hepp, 2016; Deuze, 2012). The third dimension, however, guides the empirical analysis. Following Lefebvre's understanding of space through its focus upon the material attributes that are produced through social activity (1974/1991, pp. 38ff.), I am concerned with the spatial organization of media practices and the ethical dimensions within them.

My theoretical approach is informed by a Foucauldian notion of ethics, building upon an antique, or Aristotelian, understanding of it (Foucault, Rabinow, \& Hurley, 1997). Ethics in the classic period was closely linked to cultivation, and was mainly related to one's relation to oneself, although it was also a social practice (Foucault, 1986; Foucault et al., 1997, p. 266). Ethos was 'a way of being and about behavior...a mode of being for the subject along with a certain way of acting, a way visible to others' (Foucault et al., 1997, p. 286). To care for oneself was both a privilege and a duty that guaranteed freedom by forcing individuals to diligently make themselves their own objects of life (Foucault et al., 1997). As part of the 'ethical turn' within anthropology (Brown, 2016; Zigon, 2007), the Foucauldian approach to ethics has been conceptualized as 'an ethics of the ordinary' (Faubion, 2011; Lambek, 2010).

An ethics of the ordinary builds upon a belief that ethics cannot be found in abstract principles or criteria, as ethics is rarely considered or consciously thought about, if at all, but should be searched for in people's negotiations, articulations and everyday practices (Zigon, 2007). This means ethics is 'tacit, grounded in agreement rather than rule, in practice rather than knowledge or belief, and happening without calling undue attention to itself' (Lambek, 2010, p. 2). Such an approach to ethics is particularly useful in relation to a mediatized everyday life, as the complex structure of media and society today is increasingly difficult to grasp for ordinary users, perhaps even leading to a 'moral blindness' (Bauman \& Donskis, 2013), and as the adaptation to and indispensability of digital media means profound transformations of social practice (Jansson, 2013). Our understanding of the current media culture may thus benefit from searching for ethics in the underlying values and virtues implicit in people's deeds and doings, feelings and emotions, rather than in pre-formulated principles and rational guidelines.

Foucault distinguished four dimensions of the care of the self; 1) Ethical substance; 2) Mode of subjectivity; 3) Techne, and 4) Telos (Foucault et al., 1997, pp. 262-269). I here focus upon the third dimension; techne; the self-forming activities that people conduct in order to cultivate themselves as ethical beings. Techne relates to the body, and economic as well as social relations (Foucault et al., 1997), but here it includes all the things people do in relation to digital media. An ethics of the ordinary is thus inherent in the values and virtues of everyday practice, and must be searched for in what we do (and do not do) as well as in how we articulate and embody everyday life. In the analysis outlined below I have focused on the 1) mundane media practices of 2) individuals and/in their relations to social groups to c) maintain the values and virtues of the tempo-spatial as part of an everyday ethics.

\section{Analyzing the Ethics of Space: Materials and Methods}

In order to understand the values and virtues of digital media practice I have conducted semi-structured interviews and focus group interviews with 35 Swedish individuals. The two methods were combined in order to gain knowledge about both individually organized everyday practices as well as more joint dimensions of social space. Four of the interviewees were interviewed individually, two of them were interviewed together, and the remaining 29 in smaller groups (3-5 individuals in each group). Twelve of the interviewees were male and 23 were female and their ages ranged from 19-68 years. I conducted the interviews in 2015, and the interviewees were chosen in order to reach a varied sample in relation to age, gender, class, and urban versus rural lifestyleswhich does however not make the material generalizable in any sense.

The interviews had an open character, but searched for detailed descriptions of the respondents' media use, with a particular focus upon the negotiations, practices and discourses concerning a 'good life'. In order not to direct or affect the interviews in relation to accepted discourses around the ethics of digital media, the interviews were structured around open questions about everyday media use; what, when and where, in order to let the respondents tell detailed stories about the devices and applications they used, how they and their technologies moved in space during the day, for what purposes, and the ways in which they organized it and reflected about it. Follow-up-questions gave great opportunities to deepen unexpected themes, such as the sensorial organization of space outlined in the analysis below. Generally, and ex- 
pectedly, the individual interviews provided the best and most detailed information regarding mobility and organization of space whereas the group interviews have been more useful in revealing the discourses surrounding such practices. All interviews took 1-2.5 hours and have been fully transcribed.

\section{Ethics as Sensorial Organization of Social Space}

The importance of material dimensions of media use has been on the agenda since Hermann Bausinger's groundbreaking article of media and everyday life from the late 1970s (1984). This strand of research has gained interest at the outskirts of media research for a long time but has gained increased attention lately, with the emergence of portable, mobile media (cf. Pink \& Leder Mackley, 2013; Richardson \& Hjort, 2017). Shaun Moores has, for a long time, argued for and demonstrated how the materiality of media technologies is an essential aspect of how we use, live with, and perceive media (1993, 2012). In his work on the roles of the media in everyday life he puts forward Maurice Merleau-Ponty's bodily phenomenology, putting the embodied dimensions of media use forward as vital for our understanding of it. Moores has used this approach to particularly understand media geography, everyday space-making and feelings of 'at-home ness' (Moores, 2012). But this mundane and practice-based dimension of media use is also essential for our understanding of the values and virtues crucial in the construction of a good life. In order to understand everyday media ethics from an 'ordinary' point of view, the interviews showed we must take into account the material and embodied aspects of how we live with the media in everyday life. 'Techne' of everyday media use from the interviewees' point of view is mainly related to the material dimensions of digital media, rather than its various kinds of content, provided connections, etc. Given the small, but deep, empirical material used for the analysis, it is not meaningful to discuss levels of structuration in the material based on aspects such as gender, age, class, etc. But since the individuals interviewed were chosen to represent a broad range of people and lifestyles their everyday media use also varied greatly. It is also noticeable that even though it is not possible to make any claims about gender differences in this respect, women have articulated most of the quotes used in the analysis. We know from earlier research that moral concerns about media use are more frequently articulated by women than by men (Jensen, Schrøder, TopsøeJensen, \& Stampe, 1993; Steiner, 1963), which explains this fact. The analytical points made here reveal an important dimension in our understanding of digital media ethics that has rarely gained academic attention before (even though the statistical significance cannot be verified). In the following I will demonstrate and discuss how the 35 interviewees construct a sensorial organization of space as part of an everyday ethics, individually as well as in relation to others.
Many interviews revealed the close relationship between digital media devices and the human body in readily observable ways. The relationship was not only discursively formulated but also bodily performed during the interviews. Using words to describe actions often turned out to be insufficient for the interviewees, or at least not the best means of communication. Many of the respondents suddenly stopped talking and turned to wordless movements in order to explain and clarify their media use, and to silently demonstrate how they interact bodily with their media technologies. Digital media today are mobile, portable, and conveniently small. They can be taken anywhere, and many of the interviewees, particularly (but not only) the younger ones, claimed to carry their devices with them always and everywhere, something experienced as problematic by several of them. The mobility and accessibility of digital technologies (particularly mobile phones, but also other devices) means that they are experienced and performed as visible and direct extensions of the human body (cf. McLuhan, 1994), and used for wordless, bodily communication.

Digital media are not only portable and mobile, but also themselves in motion: they vibrate, shake, and so forth. They are constructed to be noticeable, making little sounds and starting to move as soon as they need attention from their user. These notifications of various kinds-sound, movement, lights, etc. - thus speak to different parts of our minds and bodies. There are technological ways to handle this, such as mute functions, light dimmers, and so forth, but these specific characteristics of digital media make them difficult to ignore, especially as they are often carried around close to the body and are thus registered by several different senses. In order to live according to their values of a good life, the respondents constructed a sensorial organization of their everyday spaces, where they organized their own media practices. Here, organization means using the facilities provided by the technologies themselves to control the media devices, as well as organizing spaces in individual, and socially agreed-upon ways.

\subsection{Sensorial Media in Individual and Social Space}

One of the easiest, and likely most frequent, ways to organize how communication technologies give notification (often smoothly provided by the devices themselves) is to silence them. Regulating the sound of digital devices is culturally well-known and frequent, and in several public environments (such as in theatres, lecture halls, etc.), people are kindly asked by to mute their digital technologies to not disturb others or the joint activity that is going on in the room. In these cases it has to do with controlling and adjusting media technologies in order to obey the cultural frames of various kinds of social space. Similar ways of creating space for social purposes (such as intimate talks, family gatherings, romantic dinners, etc.) were also revealed in the interviews. Several discussions about the use of media technologies when among others 
revolved around the presence and noticeability of media technologies, and how that affected the social situation. Earlier research has shown that talking on the phone during a dinner with your partner is considered very inappropriate by people of all ages, likely because it breaks the boundaries of the intimate space the dinner was supposed to create (Bengtsson \& Johansson, 2015).

Making media technologies temporarily mute in specific situations or time frames is a much-used way to control their influence over ones attention and behavior in space. Besides regulating the sound of media technologies in relation to the specific spaces the respondents walk in and out of, media technologies may also be used to construct space for specific purposes, such as concentration, attention, and relaxation. One respondent, a female student, tells how she has removed the notifications of the social network apps on her phone in order to be able to make space for her studies. She felt a need to remove sounds and other kinds of notifications to be able to concentrate and pay her full attention to her study tasks. This does not mean she stopped using her social network applications, only that the lack of notifications from the technology made her keep control of herself, and to make space for her work. These practices have helped her control her own individual time and space, as she decides when she and her phone are in a 'study hall', or in a space for relaxation. Removing the apps and aural notifications from her phone makes that decision her own, regardless of the physical space she is in:

I really do love my iPhone, but I try to restrict my own use a little. I have removed all notifications, apart from text messages, because I feel I need a little mindfulness. Otherwise everything just sprawls, it just points in all different directions, and then I can't focus. And it's similar with Facebook. I think of it as if I have studied hard for an exam it's okay to go in there as a reward. At that time I can revel in Facebook and afterwards I just log out again. Otherwise the screen keeps binging and I can't focus then. (Female student, 23)

The dilemma that the student is handling is not least due to the fact that digital media devices today host many different activities at the same time: they are not only used to communicate with friends and get access to information, but also for downloading and reading study material, etc. Particularly young users claim to use their media devices for a very large number of everyday tasks, from connecting, searching, gaming, watching, being entertained, etc., which then urgently calls for a new way of symbolically moving between everyday spaces. Actively avoiding notifications is put forward as a way to keep focus in life by other interviewees also. Removing entire applications that by their sheer existence call for attention is another way to make it more technologically difficult to use them, but that helps to keep the broader balance in life, something this female priest tells about:
My wife decided to remove the Facebook app from her phone, to make it more difficult to go into Facebook. She can still log in on her phone via the Internet, but then it is a couple of more clicks. She says it helped her a lot. (Female priest, 35)

Other respondents, however, do not feel as intimately entangled with their technologies, and thus instead use the material spaces they are in to keep the media out of sensorial reach. Placing media devices somewhere where you cannot see them, out of sight, is another exercise in the search for a good life. This can be done in relation to both individual and social space. One warehouse worker in his fifties tells about how his own or others' mobile phones, even though they are muted, keep stealing attention during work meetings by turning the lights on and off, winking, etc. He and his colleagues have decided that during meetings devices are best kept in bags, pockets, or elsewhere out of sight in order not to affect the social situation. A female office clerk reveals her strategies to hide her mobile phone in her own private office space, in order to be focused at work.

\section{I: Do you only turn it off at night?}

No, I don't [turn it off] but I keep it in my purse or in my wardrobe at work, or in the pocket of my coat, or so. I'm not carrying it around or anything and it can take [a lot of time before I check it]. When I go home I always look at it and then 'oh, someone called me!'. When I'm in my office I hear when it rings, but I don't have to have it on me all the time and I don't think I need to be available 24 hours. (Female office clerk, 50)

Even though the materiality of media has always been central to how they are phenomenologically perceived, as Shaun Moores' important work has demonstrated (2012), the haptic dimensions of media devices, such as vibrating, beating, etc., are today perhaps an ever more essential characteristic of digital technologies (cf. Richardson \& Hjort, 2017). Digital media keep calling for attention from their users even if they have been muted, darkened, or put away, etc. Many of the interviewees share experiences of their own and others' media technologies that start vibrating in someone's pocket and direct everyone's attention to it, in social spaces such as work situations as well as at home or elsewhere. Lina, a single mother, tells that in order to keep the family dinner media free and a space where her family members share an experience, she forces her teenagers to put their phones away from the dinner table, in a place where they can neither be seen, heard, nor physically acknowledged.

I don't have to bring my phone to the dinner table, and if it would bring I wouldn't fly up to immediately check it [whenever something happens]. But my kids 
have theirs in their pockets or on their laps. And there are constantly friends who...I have to tell them sometimes that they don't have to answer immediately, or answer [at all]....But it is really difficult for them not to be able to have it on, very close, like this [shows, on her lap], when we eat. I think that is terrible. (Female nurse, 47)

\subsection{Mobile Micro-Space: A 'Room of One's Own'}

So far, an 'ordinary' media ethics has been discussed as various sensorial organizations of media technologies in individual and social space as part of the construction of everyday life. This does not only involve spatial or sensorial restrictions of the media, but rather ways to organize and use the media in order to create space that keeps parts of the world away. The multisensory character of digital media can thus be used to construct a mobile micro-universe to relieve stress, breathe, and take a break from an otherwise demanding environment. In a group discussion, some respondents discussed how they sometimes use their media devices as part of a social strategy to avoid certain kinds of interactions, such as pretending to be occupied with their technologies in order not to be addressed by strangers on the subway. But for others, media technologies really provide an alternative space that can be used as a 'room of one's own' in everyday life. Jessica, a recruiter in her forties, uses Facebook as a place to go when she needs a pause in an otherwise stressful everyday life:

I think it is relaxing. A break from everything else. Like going in...I can do that if I'm too stressed. Breathe a little. (Female recruiter, 42)

The most noteworthy example here is a group of female priests between 30 and 50 years old, who shared their experiences of regularly using an application called 'Pray as you go'. They described the morning journey on the subway as normally very crowded, when their bodies were involuntarily pressed against (unknown) others. This unpleasant feeling of bodily proximity was handled with this application that provided them with an alternative symbolic space.

It's just so amazing! This morning I had such an experience when people were standing like packed sardines on the green (metro) line. But this is as if you enter another room, of your own. Sometimes I have had to take my earphones out to check if anyone hears this? But, no, they don't (ha-ha)! (Female priest, 35)

\subsection{The Values and Virtues of Sensorial Organization of Space}

Domestication theory has shown how new technologies gradually find their space within households and family life (Silverstone, Hirsch, \& Morley, 1994). Smaller, more personal, and more mobile media has made this negotiation of the role of media technologies in everyday life an increasingly individual process, but as the analysis above shows, the process also in many respects has social dimensions. As many (but not all) digital media devices today are small and personal, the way they appropriate space is through different audiovisual and haptic expressions, rather than statically, as furniture in a room. The way they fill and transform space is mainly related to sounds, lights, and movements, an aspect of them that can easily be regulated by their users, and controlled in relation to both work and leisure, meetings, as well as other socially shared spaces. Interviewees discussed how the aural, visual and haptic expressions of different digital devices often break the social bonds between individuals and groups, by directing focus from the physical environment and the social situation taking place there, and towards somewhere else. Technologies can thus be adjusted to obey the specific character of the spaces users walk into and out of, but also to transform the character of a given space and reconstruct it to adjust it to a specific purpose. The multitasking character of digital media makes these everyday strategies ever more important, particularly mentioned by the younger interviewees who claim to use their mobile phones for all different kinds of purposes; work, school work, entertainment, information, etc. This pattern of use then urgently calls for new ways of moving between the symbolic spaces of everyday life. The everyday media practices of the respondents reveal how they use their digital devices to construct and maintain space for example for concentration, attention, and control. These spaces can be constructed individually, and are sometimes mobile, but may also be used as tools to create space for different social purposes.

The most important dimension of media use in the construction of a 'good life', as revealed in the examples presented above, is that of mastering technology in order to control, and construct, space. The mutual relationship between humans and media technologies has been discussed before (cf. Turkle, 2008), but the analysis here shows how the interviewees do not only try to control their media technologies, but also use media technologies to reconstruct space and everyday life more broadly. This is done in social space as demonstrated above but also put forward as individual ways to stay focused and productive, to keep track of purposes and practices, to master technologies to maintain control of one's individual space. This individualistic approach is also visible in the construction of mobile micro-spaces, which the interviewees describe as ways to keep the surrounding world and other people out of one's personal sphere-that is, to use the media to maintain an individual space, regardless of physical movements through changing material and social spaces. The mobile and personal character of digital media, and the way they are used by the interviewees, emphasizes the creation of individual, rather than a socially organized, space, although mechanisms to ad- 
just and control space in relation to social situations and other people was also brought up in the interviews.

\section{Conclusion: A 'Techne' of Embodiment and Digital Media}

The above analysis has focused on the influence of self-forming activities (techne) on the self of ordinary Swedish media users in mundane practices of everyday life. It has revealed the importance of the sensorial dimensions of media technologies in the interviewees' experiences and constructions of everyday space, individually as well as socially. Sensorial organization of digital media works both by liberating the senses (from unwanted stimuli) and by sensorially occupying them (thus keeping other stimuli out), which directs our attention towards the material dimensions of media technologies and a phenomenology of the body. There is a long tradition of phenomenological media studies as well as a new interest in the haptic dimensions of digital media, what Richardson and Hjort (2017) have called a need to 'orient media studies towards an awareness of the critical orientation of touch' (Richardson \& Hjort, 2017, p. 1664). The analysis presented here argues for a full sensorial analysis, going beyond the limitations of touch, as all senses work in relationship to the world and a 'structuring of space and defining of place' (Pink, 2009, p. 16; Rodaway, 1994, p. 4).

Such practice-based phenomenology would start from a broad notion of sensoriality and embodiment, grounded in the everyday experiences of ordinary media users, and would pay tribute to the existentialist phenomenology of Maurice Merleau-Ponty and his acknowledgement of the body and sensations as the main subject of perception (Hockey \& Allen-Collinson, 2009; MerleauPonty, 1962). Merleau-Ponty notes that things are not merely neutral objects, but that the way people relate to the world has to do with how objects provoke certain reactions (Merleau-Ponty, 2004, p. 61). I agree with Rodaway's (1994) call to take the sensorial experiences of 'the other' (here: the media user) into account in our analysis of the ethics of space (see also Moores, 2012).

The ethically organized media practices of the interviewees (techne) discussed above show 1 ) how media users not only perceive the world through the sensorial aspects of digital technologies, but also 2) how they use the technological facilities of digital media to actively (by activating or restricting certain sensorial dimensions) construct space in particular everyday situations. This way of using media is of course not new, and we know from earlier research that analogue media have also been used for such purposes (Bengtsson, 2006). Mobile and personal digital media devices are however more individualized, not least as we can use them to construct a mobile micro-space that we bring with us when moving through material space. This thus means that even though all media are in some way social and community oriented, they may at the same time be used to severely individualize the spaces in which we dwell in everyday life.

The sensorial organization of space that the interviews reveal also emphasizes the importance of acknowledging the material and bodily dimensions of media ethics, and the ways these are carried out in the mundane practices of everyday life. To fully understand how people maintain a good life in a digital culture, we must include not only touch but also a broader spectrum of sensorial experiences and constructions of space and time. Doing so means broadening what Max van Manen (2016) has called an ethical phenomenology (p. 113) by combining it with sensory dimensions.

The approach to media ethics presented here is of course highly cultural and Howes and Classen have pointed out that senses are organized hierarchically in all cultures, and that the sensory 'profile' or 'order' of culture varies in time and space (Howes \& Classen, 1991, p. 257; Pink, 2009, p. 12). We must therefore be open for synchronic variations and diachronic transformations in this area, along with the technological development of digital media.

\section{Acknowledgments}

I am grateful to the two anonymous reviewers whose constructive feedback and clarifications helped improve the text.

\section{Conflict of Interests}

The author declares no conflict of interests.

\section{References}

Bauman, Z., \& Donskis, L. (2013). Moral blindness: The loss of sensitivity in liquid modernity. Hoboken, $\mathrm{NJ}$ : John Wiley \& Sons.

Bausinger, H. (1984). Media, technology and daily life. Media Culture \& Society, 6(4), 343-351.

Bengtsson, S. (2006). Symbolic spaces of everyday life. Nordicom Review, 27(2), 119-132.

Bengtsson, S., \& Johansson, B. (2015). Mediemoral i en digital värld [Media morality in a digital world]. In A. B. Bergström, H. Johansson, \& M. Oscarsson (Eds.), Fragment (pp. 551-559). Gothenburg: SOMinstitutet.

Brown, B. E. (2016). Routines of morality: Nurturing familiar values in unfamiliar lands. Ethnography, 17(1), $3-21$.

Couldry, N. (2006). Listening beyond the echoes: Media, ethics, and agency in an uncertain world. Boulder, CO: Paradigm.

Couldry, N., \& Hepp, A. (2016). The mediated construction of reality. Hoboken, NJ: John Wiley \& Sons.

Deuze, M. (2012). Media life. Cambridge: Polity.

Faubion, J. D. (2011). An anthropology of ethics. Cambridge: Cambridge University Press. 
Foucault, M. (1986). The history of sexuality vol. 3: The care of the self (R. Hurley, Trans.). New York, NY: Pantheon.

Foucault, M., Rabinow, P., \& Hurley, R. (1997). The essential works of Michel Foucault, 1954-1984 (Vol. 1). London: Allen Lane.

Hockey, J., \& Allen-Collinson, J. (2009). The sensorium at work: The sensory phenomenology of the working body. The Sociological Review, 57(2), 217-239.

Howes, D., \& Classen, C. (1991). Sounding sensory profiles. In D. Howes (Ed.), The varieties of sensory experience: $A$ sourcebook in the anthropology of the senses (pp. 257-288). Toronto: Toronto University Press.

Jansson, A. (2013). Mediatization and social space: Reconstructing mediatization for the transmedia age. Communication Theory, 23(3), 279-296.

Jensen, K. B., Schrøder, K., Topsøe-Jensen, J., \& Stampe, T. (1993). Når danskere ser tv [When the Danes watch TV]. København: Samfundslitteratur.

Lambek, M. (Ed.). (2010). Ordinary ethics: Anthropology, language, and action. New York, NY: Fordham University Press.

Lefebvre, H. (1991). The production of space (D. NicolsonSmith, Trans.). Oxford: Blackwell. (Original work published 1974)

van Manen, M. (2016). Phenomenology of practice: Meaning-giving methods in phenomenological research and writing. London: Routledge.

McLuhan, M. (1994). Understanding media: The extensions of man. Cambridge, MA: MIT Press.

Merleau-Ponty, M. (1962). Phénoménologie de la perception [Phenomenology of perception]. London: Routledge.
Merleau-Ponty, M. (2004). The world of perception. London: Routledge.

Moores, S. (1993). Interpreting audiences: The ethnography of media consumption (Vol. 8). London: Sage.

Moores, S. (2012). Media, place and mobility. Basingstoke: Palgrave Macmillan.

Pink, S. (2009). Doing sensory ethnography. London: Sage.

Pink, S., \& Leder Mackley, K. (2013). Saturated and situated: Expanding the meaning of media in the routines of everyday life. Media, Culture \& Society, 35(6), 677-691.

Richardson, I., \& Hjort, L. (2017). Mobile media, domestic play and haptic ethnography. New Media and Society, 19(10), 1653-1667.

Rodaway, P. (1994). Sensuous geographies: Bodies, sense and place. London: Routledge.

Silverstone, R., Hirsch, E., \& Morley, D. (1994). Information and communication technologies and the moral economy of the household. In E. Hirsch \& R. Silverstone (Eds.), Consuming technologies: Media and information in domestic spaces (pp. 13-28). London: Routledge.

Steiner, G. A. (1963). The people look at television: A study of audience attitudes. New York, NY: Knopf.

Turkle, S. (2008). Always-on/always-on-you: The tethered self. In J. E. Katz (Ed.), Handbook of mobile communication studies (pp. 220-259). Cambridge, MA: MIT Press.

Zigon, J. (2007). Moral breakdown and the ethical demand: A theoretical framework for an anthropology of moralities. Anthropological Theory, 7(2), 131-150.

\section{About the Author}

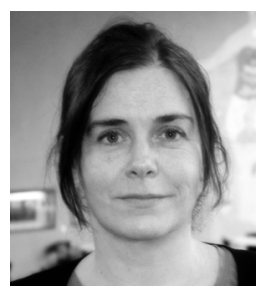

Stina Bengtsson is Associate Professor of Media and Communication Studies at Södertörn University, Stockholm, Sweden. Bengtsson has conducted research about media and everyday life; ethics, morality and the media; virtual cultures, media and space, etc. She has led several research projects on media use in different cultural contexts, online as well as offline, and has published several books, and articles in journals such as Media, Culture and Society, Space and Culture, International Journal of Cultural Studies, etc. 